\title{
Physical activity patterns in older men and women in Germany: a cross-sectional study
}

\author{
Anna Moschny ${ }^{1 *}$, Petra Platen ${ }^{1}$, Renate Klaaßen-Mielke ${ }^{2}$, Ulrike Trampisch ${ }^{1}$ and Timo Hinrichs ${ }^{1}$
}

\begin{abstract}
Background: Data on physical activity in older adults in Germany is scarce. The aim of this study was to analyze physical activity patterns and to explore factors associated with physical activity in different domains, i.e. sporting activities (SA) and domestic activities (DA), in older men and women.

Methods: As part of the 7-year follow-up telephone interviews of the getABI cohort (community-dwelling older adults in Germany), the PRISCUS-PAQ was used to survey participants about their everyday physical activity patterns. Time per week (hh:mm) spent in SA and DA (heavy housework, gardening) was analyzed for men and women. Multivariate logistic regression analyses were performed in order to assess the odds of participating in SA and DA for at least 2.5 hours/week in association with sociodemographic factors, a broad range of physical healthrelated factors and interview date (season of the year).
\end{abstract}

Results: A total of 1,610 primary health care patients (51.6\% women) with a median age of 77 (range $72-93$ ) years were included in the analyses. Men engaged in SA more often than women (01:45 vs. 01:10), whereas women did more DA per week than men (04:00 vs. 03:00).

Being interviewed in spring or summer was associated with increased performance of DA in both sexes.

Participation in these activities was reduced in more highly educated men and women. Living alone increased the odds of sports participation in women, but not in men. Most physical health-related factors were only selectively associated with either SA or DA, in men or women, respectively. The need for a walking aid was the only factor that consistently lowered the odds of being active in both activity domains and sexes.

Conclusions: This exploratory study delivers reliable and relevant data on the participation in and correlates of sporting and domestic activities of community-dwelling older adults for whom there had previously been only limited information at a population level in Germany. Findings are discussed and implications for epidemiological research and health promotion practice are provided.

Keywords: Aged, gender, physical activity, housework, gardening, correlates, public health

\section{Background}

The phenomenon of the demographic change is well known [1]. In the future, it will increasingly challenge health care systems in terms of financial and personal resources. Thus, the health status of the older population will be of particular importance. Physical inactivity constitutes a major health risk [2], whereas being sufficiently physically active has the potential to preserve or improve health and functioning [3], and in turn foster older adults'

\footnotetext{
* Correspondence: anna.moschny@rub.de

'Department of Sports Medicine and Sports Nutrition, Ruhr-University Bochum, Germany

Full list of author information is available at the end of the article
}

independence and health-related quality of life. Recently, extensive efforts have been made to summarize the compelling evidence regarding the multifaceted health benefits of regular physical activity and exercise, even for previously sedentary and chronically diseased older people [4,5]. In light of the new evidence, the updated "2008 Physical Activity Guidelines for Americans" [6] emphasize that health benefits are not only derived from sports and exercise. Lifestyles that are generally active, including domestic activities such as housework and gardening, are considered to be beneficial as well. In order to derive reasonable health promotion and intervention strategies, both insights into physical activity patterns of specific

\section{() Biomed Central}


population subgroups and a deeper understanding of the determinants of physical activity are needed.

To date, little is known about the physical activity behavior of older adults in Germany. The German National Health Interview 2003 [7] and the German annual telephone survey 2009 (GEDA) [8] assessed sporting activity for the adult population. The low levels of sporting activity for older adults revealed by these studies are consistent with international epidemiological research [9-16]. However, studies focusing exclusively on sports and exercise overlook activity domains that are particularly important for people in old age. Research explicitly exploring physical activity patterns in the elderly population identified heavy housework and gardening as among the most common activities performed [13,14,17-21]. It has been suggested that these everyday activities compensate for the decline in sports and exercise observed with increasing age. However, for Germany, so far only one study has been published to date that considers different activity domains that are relevant for older adults [22].

The participation in different physical activities is considered to be influenced by a complex interaction of sociodemographic, physical, psychological, social, environmental and sociopolitical factors [23,24]. Although many studies examined potential determinants of physical activity, little research focused on older adults [24]. Therefore, observations regarding the predictors of physical activity in this population group are rare and those that exist are largely inconsistent, especially when relating to different categories of physical activity.

Physical health status is one of the most important determinants of physical activity behavior in aging. Poor health is the barrier to physical activity cited most often by older adults $[25,26]$ and has been shown to predict the initiation and maintenance of physical activity in this population [24]. However, no detailed analyses regarding the influence of physical health-related factors on physical activity exist. Most studies that have been published either considered the influence of the mere number of chronic conditions on physical activity [19,27], or only took a limited number of (chronic) physical ailments into account $[15,28,29]$. We hypothesize that specific chronic conditions or specific physical health-related factors such as pain or limited lower body function may differently impact physical activity, i.e. sporting or domestic activity. Knowledge about the associations between these specific factors and physical activity may facilitate targeted interventions in health care.

Since gender is one of the most consistent factors influencing physical activity [30], it would be reasonable to examine potential determinants of physical activity separately for men and women in order to obtain insights on gender-related activity behavior. Differentiated analyses of different activity domains would help to gain deeper understanding of participation in various activities. However, existing studies examining the potential determinants of physical activity among older adults either focused on one type of activity, studied only men or women, or displayed results for total activity or combined the results for both sexes $[11,14,15,17,19-21,27,28,31-33]$. To the authors' knowledge, no research has been published to date that simultaneously investigated factors associated with sporting activity and domestic activity in older men and women, respectively.

Consequently, the first aim of the study was to analyze engagement in sporting and domestic activities of older men and women in Germany. The second aim was to explore factors - physical health-related factors in particular - associated with performance of sporting and domestic activities separately by sex.

\section{Methods \\ Design and participants}

The "German epidemiological trial on ankle brachial index" (getABI) is a prospective, large-scale observational study. Its design and methods have been described elsewhere in greater detail $[34,35]$. In brief, each of the participating 344 general practitioners consecutively recruited on average 20 eligible patients who sought primary health care during a predefined week in October 2001 and fulfilled the inclusion criteria (age $\geq 65$ years, being legally competent and able to co-operate appropriately, and providing written informed consent). The only exclusion criterion was life expectancy $\leq 6$ months. A total of 6,880 community-dwelling primary health care patients were included in the study. Within the 7-year follow-up period, 1,302 patients died. The remaining 5,578 patients were contacted by letter and by one telephone call to evaluate their willingness to participate in the computer-assisted telephone interview at the 7-year follow-up. One hundred and ninety-six patients were unable to participate in the interview; another 3,445 patients did not participate in the interview for several other reasons (not reachable, did not want to be contacted by telephone, refused to participate in the telephone interview). In the end, a sample of 1,937 patients (response rate $34.7 \%$ ) took part in the telephone interviews at the 7-year follow-up. A comparison of these participants to non-participants revealed the following significant differences: participants were younger at baseline (median age (range): 70 (65-85) years vs. 72 (65-91) years), were more often male ( $46.7 \%$ vs. $35.7 \%)$, and were better educated (qualification higher than basic secondary school: $40.2 \%$ vs. $27.1 \%$ ). Results reported in this paper predominantly refer to cross-sectional data collected during the 7-year follow-up interviews.

The study was approved by the University of Heidelberg and the University of Bochum (Germany) ethics committees, and was conducted according to the "Good 
Epidemiological Practice" recommendations issued by the "German Working Group Epidemiology" [36].

\section{Outcomes \\ Physical activity}

As part of the telephone interviews of the 7-year follow-up subjects were surveyed on their everyday physical activity patterns using the PRISCUS Physical Activity Questionnaire (PRISCUS-PAQ) [37]. To ensure appropriateness of physical activity-related questions, participants were initially asked about their walking ability in the week prior to the interview. Evaluation revealed that five interviewees were either wheelchair-bound or bed-ridden, and were thus not queried about their physical activity. To guarantee valid data concerning usual physical activity patterns, those 137 participants who specified that they had been markedly restricted in their physical activities in the preceding week due to a current incident (e.g. fall, accident, severe flu) were also excluded from physical activity questions. One participant who did not provide specific information for either of the two questions was also excluded. In the end, 1,794 patients could be interviewed concerning their everyday physical activity. They did not vary in age and sex from participants who were excluded.

Detailed information on the development, the structure and the reliability of the 10-item PRISCUS-PAQ has already been published [37]. In summary, all questions referred to the prior week except for the item on gardening, which referred to the prior two weeks to account for short-term weather variations. Participants had to state the number of days for each activity and the mean duration for activities performed. Time per week (hh:mm) was then calculated for the single items and for activity categories.

With regard to the purpose of the study, the items bikeriding, exercises and/or strength training, organized sports groups, and other sporting and leisure activities that caused sweating were subsumed under the category "sporting activities." Heavy housework and gardening will be referred to as "domestic activities."

The new 2008 Physical Activity Guidelines recommend an accumulation of at least 150 minutes of moderateintensity activity in order to bring about health benefits [6]. This benchmark was used for binary categorization of respondents as active ( $\geq 2.5 \mathrm{hrs} / \mathrm{wk})$ and insufficiently active or inactive $(<2.5 \mathrm{hrs} / \mathrm{wk})$.

\section{Covariables}

The main covariables were sociodemographic and physical health-related factors. Season (interview date) was included as an environmental variable.

\section{Sociodemographic factors}

At baseline, the general practitioner documented the participants' sex, date of birth and educational level (no qualification - completed basic secondary school - vocational school - university entrance qualification). During telephone interviews, participants were surveyed about their native country (5-year follow-up) as well as the number of persons living in the same household (7-year follow-up).

\section{Cardiovascular risk factors}

Waist circumference was measured by the general practitioner using a standard protocol at the 5-year and the 7year follow-up of the getABI cohort. Waist circumference at 7-year follow-up was used for analysis. If values were missing, waist circumference at 5-year follow-up was used. The current smoking status was documented at baseline (smoking no/yes).

The following covariables were assessed in the course of the 7-year follow-up telephone interviews:

\section{Chronic conditions}

Participants were asked whether they suffered from any of the following chronic diseases (no/yes): arterial hypertension, coronary heart disease, myocardial infarction, chronic heart failure (CHF), diabetes mellitus, peripheral arterial disease, chronic obstructive pulmonary disease (COPD), arthritis (degenerative or rheumatic) or osteoporosis.

\section{Walking ability, falls and pain}

Walking ability was assessed by asking participants whether they needed a walking aid (no aid - cane - rollator - wheelchair-bound - bed-ridden). Falls were defined as "an unexpected event in which the participants come to rest on the ground, floor, or lower level" [38]. Respondents reported falls within the previous 12 months (no/yes), and pain within the past 3 months (no/yes).

\section{Season}

To encode the seasons, the interview month was extracted from the interview date. Telephone interviews held in April to September were coded as "spring/summer", those held in the remaining months were coded as "autumn/ winter".

\section{Statistical analysis}

In order to describe the getABI patients who were analyzed, the univariate distribution of categorical variables is presented in terms of absolute frequencies, percentages and p-values from Pearson's chi-square test (see Table 1). Analyses of physical activity patterns are descriptive. They include percentages for engagement in domestic or sporting activities on at least one day in the week prior to the interview, median time per week spent on the respective activities, and percentages for those performing these activities for at least $2.5 \mathrm{hrs} / \mathrm{wk}$.

Multivariate logistic regression analyses were done to assess the odds of engagement in sporting and domestic activities for at least $2.5 \mathrm{hrs} / \mathrm{wk}$ associated with sociodemographic variables, cardiovascular risk factors, chronic conditions, walking ability, falls, pain, and season. 
Table 1 Participants' characteristics at time of the 7-year follow-up by sex

\begin{tabular}{|c|c|c|c|c|c|}
\hline & \multicolumn{2}{|c|}{ Men $(n=780)$} & \multicolumn{2}{|c|}{ Women $(n=830)$} & \multirow[t]{2}{*}{$\mathrm{p}$-value } \\
\hline & $\mathrm{n}$ & $\%$ & $\mathrm{n}$ & $\%$ & \\
\hline \multicolumn{6}{|l|}{ Outcomes } \\
\hline Sporting activities $\geq 2.5$ hours per week & 325 & 41.7 & 256 & 30.8 & $<.001$ \\
\hline Domestic activities $\geq 2.5$ hours per week & 426 & 54.6 & 566 & 68.2 & $<.001$ \\
\hline \multicolumn{6}{|l|}{ Sociodemographic factors } \\
\hline Age $\geq 80$ years & 246 & 31.5 & 293 & 35.3 & .110 \\
\hline Place of birth Germany & 704 & 90.3 & 759 & 91.4 & .408 \\
\hline Educational level higher than basic secondary school & 348 & 44.6 & 323 & 38.9 & .020 \\
\hline Living alone & 126 & 16.2 & 449 & 54.1 & $<.001$ \\
\hline \multicolumn{6}{|l|}{ Cardiovascular risk factors } \\
\hline Currently smoking (baseline) & 57 & 7.3 & 54 & 6.5 & .526 \\
\hline Waist circumference ${ }^{a}$ : women $\geq 88 \mathrm{~cm}$; men $\geq 102 \mathrm{~cm}$ & 439 & 56.3 & 582 & 70.1 & $<.001$ \\
\hline \multicolumn{6}{|l|}{ Chronic conditions } \\
\hline Hypertension & 480 & 61.5 & 559 & 67.3 & .015 \\
\hline CHD and/or myocardial infarction & 265 & 34.0 & 148 & 17.8 & $<.001$ \\
\hline Chronic heart failure & 159 & 20.4 & 146 & 17.6 & .153 \\
\hline Diabetes mellitus & 213 & 27.3 & 188 & 22.7 & .031 \\
\hline Peripheral arterial disease & 101 & 12.9 & 80 & 9.6 & .036 \\
\hline Chronic obstructive pulmonary disease & 79 & 10.1 & 96 & 11.6 & .354 \\
\hline Arthritis (degenerative or rheumatoid) & 239 & 30.6 & 318 & 38.3 & .001 \\
\hline Osteoporosis & 37 & 4.7 & 171 & 20.6 & $<.001$ \\
\hline \multicolumn{6}{|l|}{ Other health-related factors } \\
\hline Need for walking aid & 110 & 14.1 & 147 & 17.7 & .048 \\
\hline Falls (past 12 months) & 131 & 16.8 & 208 & 25.1 & $<.001$ \\
\hline Pain (past 3 months) & 357 & 45.8 & 495 & 59.6 & $<.001$ \\
\hline \multicolumn{6}{|l|}{ Environmental factors } \\
\hline Season: spring/summer & 486 & 62.3 & 536 & 64.6 & .334 \\
\hline
\end{tabular}

$\mathrm{CHD}=$ Coronary heart disease

a Waist circumference at 7-year follow-up was used for analysis. If this value was missing, waist circumference at 5-year follow-up was used.

Covariables (for binary categorization see Table 2) were simultaneously entered in the four models (for each activity domain and sex, respectively). Participants with missing values in the outcomes or covariables were excluded from analyses. Evaluation of differences between cases with complete and incomplete data was performed by means of the chi-square test (Fisher's exact test). Within the logistic regression analyses, the $95 \%$ confidence interval (95\% CI) was calculated for each odds ratio (OR).

\section{Results}

\section{Participants}

Of the 1,794 participants, 184 were excluded due to incomplete data. A slightly higher number of men delivered complete data for analyses $(92.5 \%$ vs. $87.3 \%)$. Men who answered all questions more often had a higher level of education than those who did not answer completely (44.6\% vs. $22.0 \%)$. Women with complete data more often suffered from at least one chronic condition compared to those who failed to answer all questions $(89.6 \%$ vs. $82.5 \%)$. Cases with complete and incomplete data did not substantially differ with regard to age, cardiovascular risk factors, walking ability, falls, pain or season.

A total of 1,610 primary health care patients $(51.6 \%$ women) with a median age of 77 (range 72-93) years were ultimately included in the analyses. These participants' characteristics are displayed by sex in Table 1 .

\section{Physical activity patterns}

Physical activity patterns of men and women with regard to performance rates and median time per week (hh:mm) are shown in Figure 1. While the rates of engagement in sporting activities on at least one day in the week prior to the interview were comparable between men and women (67.3\% vs. 66.3\%), men spent more time per week in these activities than women did (03:30 vs. 02:20). In contrast, median time per week for those performing domestic activities was equal between the sexes although fewer men than women stated that they had done heavy housework and/or gardening in the previous week (79.1\% vs. $86.6 \%)$.

To appraise the amount of physical activity of the total samples of men and women, median time per 
Table 2 Multivariate analyses of factors associated with sporting activities and domestic activities in men and women (active [ $\geq 2.5$ hours/week] vs. inactive)

\begin{tabular}{|c|c|c|c|c|c|c|c|c|}
\hline & \multicolumn{4}{|c|}{ Sporting activities } & \multicolumn{4}{|c|}{ Domestic activities } \\
\hline & \multicolumn{2}{|l|}{ Men } & \multicolumn{2}{|l|}{ Women } & \multicolumn{2}{|l|}{ Men } & \multicolumn{2}{|l|}{ Women } \\
\hline & $\begin{array}{l}\% \\
\text { active }^{\dagger}\end{array}$ & $\begin{array}{l}\text { Adjusted } \mathrm{OR}^{\#} \\
{[95 \% \mathrm{CI}]}\end{array}$ & $\begin{array}{l}\% \\
\text { active }^{\dagger}\end{array}$ & $\begin{array}{l}\text { Adjusted OR } \\
{[95 \% \mathrm{Cl}]}\end{array}$ & $\begin{array}{l}\% \\
\text { active }^{+}\end{array}$ & $\begin{array}{l}\text { Adjusted } \mathrm{OR}^{\#} \\
{[95 \% \mathrm{Cl}]}\end{array}$ & $\begin{array}{l}\% \\
\text { active }^{\dagger}\end{array}$ & $\begin{array}{l}\text { Adjusted } \mathrm{OR}^{\#} \\
{[95 \% \mathrm{Cl}]}\end{array}$ \\
\hline \multicolumn{9}{|l|}{ Sociodemographic factors } \\
\hline \multicolumn{9}{|l|}{ Age } \\
\hline$<80$ years & 46.8 & 1 & 34.6 & 1 & 57.3 & 1 & 73.7 & 1 \\
\hline$\geq 80$ years & 30.5 & $0.52[0.36 ; 0.73]^{*}$ & 23.9 & $0.55[0.39 ; 0.78]^{*}$ & 48.8 & $0.83[0.59 ; 1.17]$ & 58.0 & $0.62[0.44 ; 0.88]^{*}$ \\
\hline \multicolumn{9}{|l|}{ Place of birth } \\
\hline Outside Germany & 51.3 & 1 & 31.0 & 1 & 50.0 & 1 & 59.2 & 1 \\
\hline Germany & 40.6 & $0.61[0.37 ; 1.01]$ & 30.8 & $1.02[0.59 ; 1.78]$ & 55.1 & $1.19[0.72 ; 1.96]$ & 69.0 & $1.47[0.85 ; 2.53]$ \\
\hline \multicolumn{9}{|l|}{ Education level (qualification) } \\
\hline $\begin{array}{l}\text { No qualification or basic } \\
\text { secondary school }\end{array}$ & 42.6 & 1 & 28.6 & 1 & 60.0 & 1 & 72.6 & 1 \\
\hline $\begin{array}{l}\text { Higher than basic secondary } \\
\text { school }\end{array}$ & 40.5 & $0.87[0.64 ; 1.19]$ & 34.4 & $1.30[0.95 ; 1.80]$ & 48.0 & $0.58[0.43 ; 0.79]^{*}$ & 61.3 & $0.68[0.49 ; 0.94]^{*}$ \\
\hline \multicolumn{9}{|l|}{ Living situation } \\
\hline $\begin{array}{l}\text { With at least one other } \\
\text { person }\end{array}$ & 42.7 & 1 & 27.0 & 1 & 54.9 & 1 & 73.2 & 1 \\
\hline Living alone & 36.5 & $0.82[0.54 ; 1.24]$ & 34.1 & $1.68[1.22 ; 2.31]^{*}$ & 53.2 & $0.97[0.64 ; 1.46]$ & 63.9 & $0.75[0.53 ; 1.04]$ \\
\hline \multicolumn{9}{|l|}{ Cardiovascular risk factors } \\
\hline \multicolumn{9}{|l|}{ Currently smoking (baseline) } \\
\hline No & 42.7 & 1 & 31.8 & 1 & 53.9 & 1 & 69.6 & 1 \\
\hline Yes & 28.1 & $0.45[0.24 ; 0.84]^{*}$ & 16.7 & $0.42[0.19 ; 0.89]^{*}$ & 63.2 & $1.25[0.69 ; 2.23]$ & 48.1 & $0.38[0.21 ; 0.69]^{*}$ \\
\hline \multicolumn{9}{|l|}{ Waist circumference ${ }^{a}$} \\
\hline Women $<88 \mathrm{~cm}$; men $<102 \mathrm{~cm}$ & 44.3 & 1 & 33.1 & 1 & 56.3 & 1 & 65.3 & 1 \\
\hline Women $\geq 88 \mathrm{~cm}$; men $\geq 102 \mathrm{~cm}$ & 39.6 & $0.82[0.61 ; 1.12]$ & 29.9 & $0.97[0.69 ; 1.37]$ & 53.3 & $0.88[0.65 ; 1.19]$ & 69.4 & $1.30[0.91 ; 1.84]$ \\
\hline
\end{tabular}

\section{Chronic conditions}

Hypertension

\begin{tabular}{|c|c|c|c|c|c|c|c|}
\hline 43.7 & 1 & 32.1 & 1 & 53.7 & 1 & 69.0 & 1 \\
\hline 40.4 & $0.88[0.64 ; 1.20]$ & 30.2 & $1.03[0.73 ; 1.43]$ & 55.2 & $1.08[0.79 ; 1.48]$ & 67.8 & $1.02[0.72 ; 1.44]$ \\
\hline 41.6 & 1 & 30.4 & 1 & 53.0 & 1 & 67.9 & 1 \\
\hline 41.9 & $1.19[0.86 ; 1.65]$ & 33.1 & $1.35[0.89 ; 2.05]$ & 57.7 & $1.35[0.98 ; 1.87]$ & 69.6 & $1.31[0.85 ; 2.04]$ \\
\hline 43.6 & 1 & 31.0 & 1 & 55.6 & 1 & 70.8 & 1 \\
\hline 34.0 & $0.74[0.50 ; 1.10]$ & 30.1 & $1.03[0.68 ; 1.55]$ & 50.9 & $0.93[0.64 ; 1.37]$ & 56.2 & $0.60[0.40 ; 0.89]^{*}$ \\
\hline 44.3 & 1 & 33.3 & 1 & 55.9 & 1 & 69.8 & 1 \\
\hline 34.7 & $0.67[0.47 ; 0.96]^{*}$ & 22.3 & $0.63[0.42 ; 0.94]^{*}$ & 51.2 & $0.81[0.57 ; 1.14]$ & 62.8 & $0.82[0.60 ; 1.22]$ \\
\hline 42.7 & 1 & 31.9 & 1 & 54.8 & 1 & 69.1 & 1 \\
\hline 34.7 & $0.89[0.55 ; 1.43]$ & 21.3 & $0.65[0.36 ; 1.20]$ & 53.5 & $1.00[0.63 ; 1.61]$ & 60.0 & $0.89[0.51 ; 1.53]$ \\
\hline
\end{tabular}

Chronic obstructive pulmonary disease

No

Yes

Arthritis (degenerative or rheumatoid)

$$
\text { No }
$$

Yes

Osteoporosis

(1)

$$
\text { (atoid) }
$$

Yes

Yes

and/or myocardial infarction

$$
\text { No }
$$

ronic heart failure

No

Yes

No

aterial disease

No

yes 
Table 2 Multivariate analyses of factors associated with sporting activities and domestic activities in men and women (active [? ?? 2.5 hours/week] vs. inactive) (Continued)

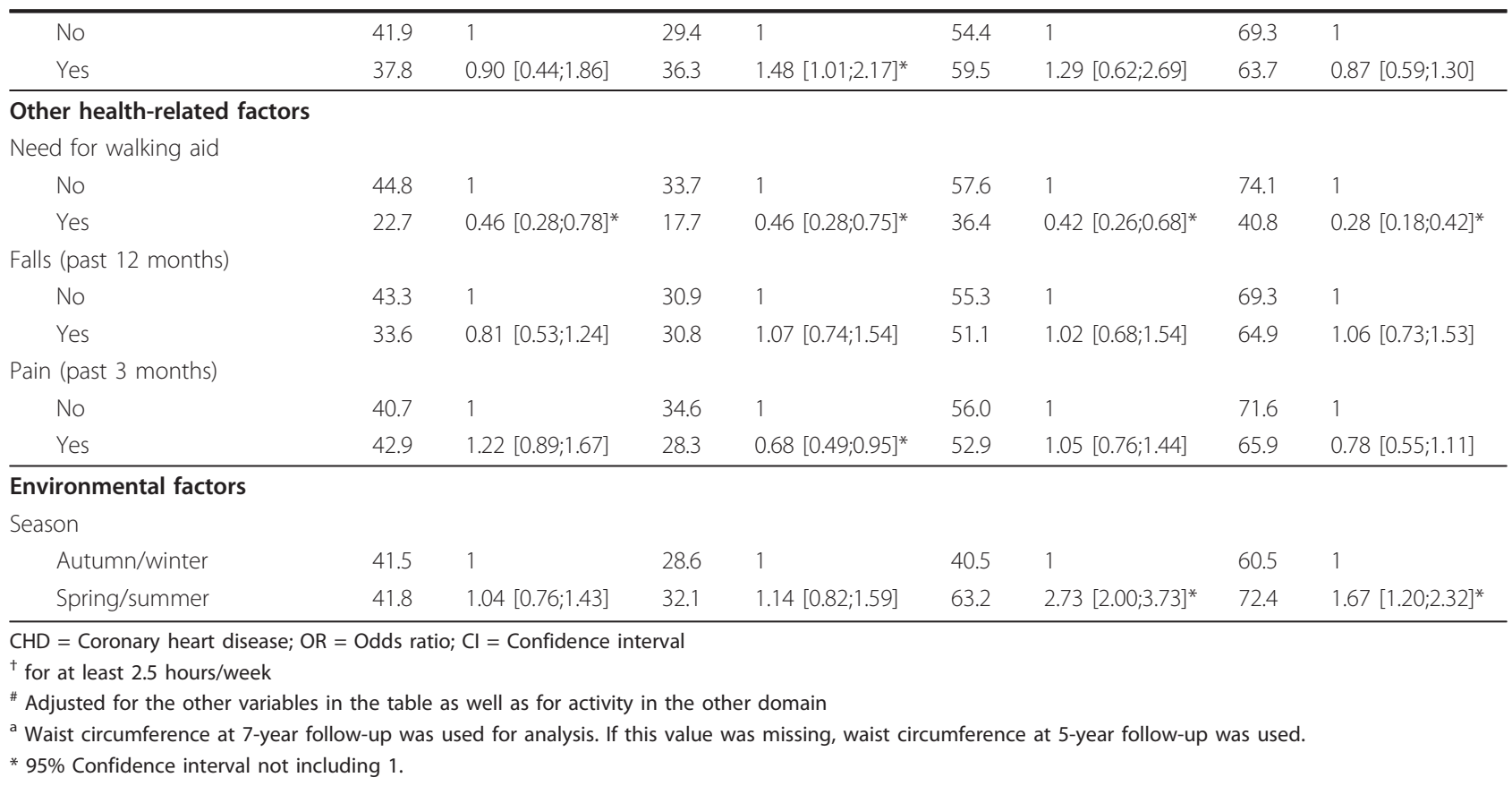

week was also been evaluated for all respondents including those who did not perform the respective activity, and thus were assigned a null for time per week. Altogether, men engaged more in sporting activities than women (01:45 vs. 01:10), whereas women performed more domestic activities per week than their male counterparts (04:00 vs. 03:00).

Accordingly, while more male than female participants reached a minimum of at least 2.5 hours/week (hrs/wk) of sporting activities ( $41.7 \%$ vs. $30.8 \%$ ), more women

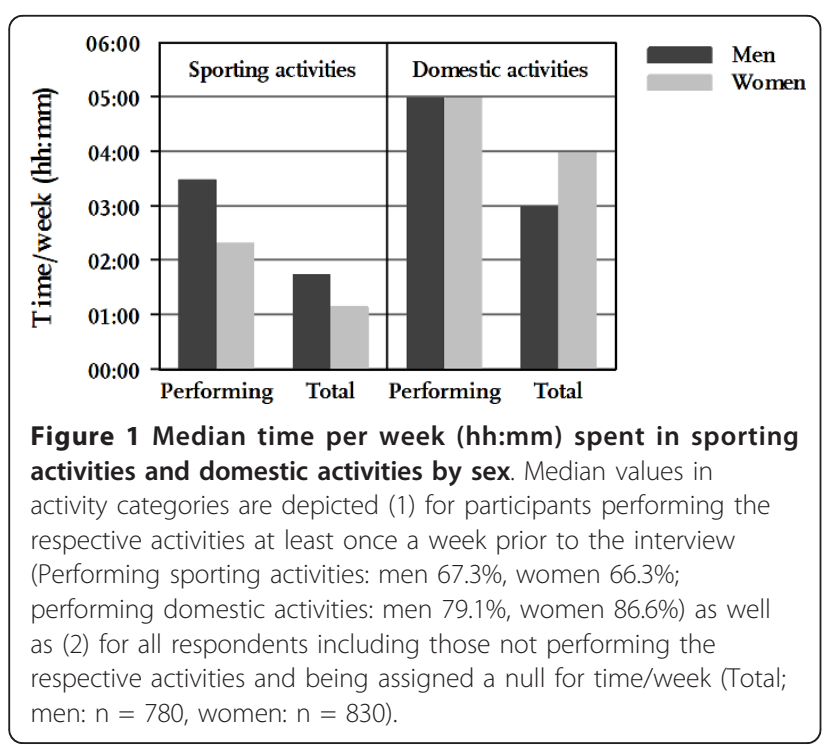

than men reached this benchmark with regard to domestic activities (68.2\% vs. $54.6 \%)$.

\section{Correlates of sporting and domestic activities}

Factors independently associated with sporting and domestic activities in men and women are shown in Table 2. Higher age and being a smoker was associated with decreased physical activity among men and women, except for men performing domestic activities. Males and females with a higher level of education had a lower domestic activity level, while there was no association with sporting activity. Living alone increased the chance of females engaging in sporting activities by nearly $70 \%$.

Regarding health-related factors, walking ability was the only factor consistently associated with reduced odds of being active in both activity domains and both sexes. Diabetes mellitus was found to lower the odds of performing sporting activities in men and women. Chronic heart failure was negatively associated with domestic activity in women, while chronic obstructive pulmonary disease was negatively associated with sporting activity in men. While female participants with pain less frequently reached the minimum amount of $2.5 \mathrm{hrs} /$ wk of sporting activity, those with osteoporosis had higher odds of sports participation, though associations were weak.

Finally, with respect to the environmental factor considered in the analyses, season was most strongly associated with activity in the house and/or garden, while it was unrelated to sporting activity. In both sexes, the following 
factors did not prove to be independently associated with either activity domain: place of birth, waist circumference, hypertension, peripheral arterial disease, arthritis, history of falls.

\section{Discussion}

This study evaluated physical activity patterns of older men and women in Germany, and explored correlates of sporting and domestic activity.

\section{Physical activity patterns}

Analyses revealed gender-related differences regarding time spent in sporting activities or domestic activities. Generally, this finding is in line with national and international data on physical activity patterns in elderly $[7,8,11,16,22,28]$.

Luehrmann et al. [22] investigated energy expenditure within a longitudinal study in an elderly population in Germany (GISELA). They assessed physical activity patterns via questionnaire and presented mean hours per day (hrs/d) spent in different activities. The study revealed that women engaged more in housework and gardening than men (women 03:40 hrs/d, men 02:06 $\mathrm{hrs} / \mathrm{d}$ ), whereas male participants spent more time in sporting activities (men 00:46 hrs/d, women 00:30 hrs/ d), supporting findings in the getABI cohort. However, when our result are considered from time/week to time/ day, much lower levels of physical activity are found in the getABI cohort in both activity domains and sexes (see Figure 1). Several aspects may have led to these discrepancies: 1 . The GISELA study presented time per day as mean values, while we decided to present the median time due to skewed data distribution in the direction of low values; mean values obviously would have been higher. 2. Regarding the category of domestic activities, Luehrmann et al. did not differentiate between light and heavy housework. In the present study, both light and heavy housework were assessed, but only heavy housework was considered for analyses accounting for merely one-quarter of total time spent on housework. 3. The GISELA study assessed time for housework and gardening per day. In contrast, the PRISCUS-PAQ first asked about the number of days on which the activity was performed in the previous week and then for mean time spent in the respective activities. Calculating time per week will consequently yield lower duration for all participants who specified that they had performed the activity on fewer than 7 days. Comparing our results to others in this field of research reveals several methodological issues that merit consideration. Specifically, the use of differing questionnaires can be problematic.

In addition, ever changing physical activity guidelines can at times affect comparability across studies when they are used as a method of categorization. Previously researchers aligned their categorization with the American College of Sports Medicine and American Heart Association (ACSM/AHA) recommendations for adults [39] or older adults [3], recommending at least $30 \mathrm{~min}$ utes of moderate-intensity activity on five, preferably on all days of the week. Since 2008, the updated guidelines released by the U.S. Department of Health and Human Services have allowed an accumulation of 150 minutes of moderate-intensity physical activity. The dilemma is that applying differing sets of recommendations to categorize subjects as active or inactive yields different results $[12,40,41]$. Researchers from the U.S. Centers for Disease Control and Prevention [40] analyzed data of the 2007 Behavioral Risk Factor Surveillance System (BRFSS), applying both above-mentioned sets of recommendations. $64.5 \%$ of respondents met the 2008 Guidelines, while only $48.8 \%$ of the same respondents were classified as sufficiently active according to the older benchmark of getting physical activity at least 5 times a week for 30 minutes or more [40]. This methodological problem also becomes evident in the following comparisons of our results to the results from existing German studies that assessed prevalence of physical activity in old age.

Using the German National Health Interview 2003 [7], researchers revealed the following rates of sports engagement for the age group 70-79 years: men $29.9 \%$, women $22.2 \%$; at least 2 hrs/wk: men $15.5 \%$, women $17.5 \%$. GEDA 2009 [8] showed that performance rates have increased. In the age group 65 years and older, $35.2 \%$ of men and $29.2 \%$ of women engaged in sports for a minimum of $2 \mathrm{hrs} / \mathrm{wk}$. Although participants in the present study needed to accumulate at least $2.5 \mathrm{hrs} / \mathrm{wk}$ of sporting activities, rates in the getABI cohort were higher (men $41.7 \%$, women $30.8 \%$ ). These differing performance rates may be attributed to the way questions are posed. In the getABI study, respondents were asked for activities such as bike-riding, exercises or strength training, participation in organized groups, or performance of other leisure activities that caused sweating, the German National Health Interview and GEDA 2009 assessed sporting activity based on a single item: "How often did you perform sports in the past week?" and "Think about the past three months. Did you perform sports during this period?" It may be assumed that people in old age interpret the term "sports" quite differently. Various activities, such as gymnastics or dancing may not always be considered to be sporting activities. As a consequence, this may have led to an underreporting of performing sporting activities in the two German studies cited. Finally, despite methodological problems hampering comparisons between studies, the findings from the current study fit into an overall epidemiological picture of physical activity in old age. 


\section{Correlates of sporting and domestic activity Sociodemographic factors}

According to the updated review on correlates of adults' participation in physical activity [30], higher age is consistently associated with lower physical activity. This was also the case in our study, although the association between higher age and lower domestic activity in men was not significant. In the present study, age was not associated with domestic physical activity in men. However, even when age is found to be independently associated with lower activity, as is the case here for women, age itself is never the factor influencing physical activity. There are rather underlying physiological (e.g. decreased physical functioning), psychosocial (e.g. attitude towards physical activity in old age, fear of crime or injury, social support) or environmental factors (e.g. no place to sit down, no/uneven sidewalks) explaining decreasing activity with increasing age.

Education has been shown to be strongly positively associated with physical activity [30]. However, the present study found contradicting results. While there was no significant association between educational level and sporting activity in our study, domestic activities were significantly less frequently performed by more highly educated men and women. A study in older women from the U.K. [14] confirmed that belonging to the managerial and professional class was associated with doing significantly less heavy housework compared to women from the intermediate and working class. We speculate that better education may result in higher income, and thus the possibility to pay others to do household chores, or the gardening is plausible.

Living alone was a factor independently associated with increased sporting activity in women. Comparisons with other findings are difficult for several reasons. Researchers usually assessed marital status $[11,14,31,32,42]$, which precludes statements on whether the older person is living on his/her own, or with others. Furthermore, there is no German study available regarding the association between living alone and the level of sporting activity in elderly men and women. One study among Swedish elderly assessed the level of outdoor recreational physical activity - comprising sporting activities, gardening, and walking and associated factors [43]. In contrast to our results, there was no independent association of living alone and outdoor recreational physical activity level in either men or women. Another study investigating overall physical activity in 72 older Australian women found those living alone to be significantly more active [44]. Although it did not focus on sporting activities and did not study both sexes, this study supports the findings in female getABI patients. The patient characteristics in Table 1 show that many more female getABI patients than male getABI patients stated that they lived alone (54.1\% vs. $16.2 \%)$.
Consistent with our analyses is the fact that $49 \%$ of women but only $17 \%$ of men aged 65 years and older were living alone in Germany in the year 2004 [45]. The Contribution to Federal Health Reporting entitled Health and Morbidity in Old Age [46] pointed out that the living situation for older women turns out to be fundamentally different compared to older men. With increasing age, the rate of widowed women rises dramatically, since at the age of 80 years and older, three-quarters of all women are widowed. The rate of older adults who are single and divorced is also higher in women than in men [46]. In sum, more older women than men have to cope with the situation of living alone. However, compared to men living alone, older women appear to more actively participate in social life, to be more motivated and engaged in arranging their future phase of life, and more often consider reorientation [47]. It is thus possible that engagement in sporting activities, which may go along with building (new) social networks, is one way for women to cope with the (often long-lasting) situation of living alone.

\section{Season}

The factor most strongly associated with increased odds of being active in the house and/or garden was being interviewed in spring or summer (SS) as compared to autumn or winter (AW). This was true for both men and women. As expected, these associations in the category of domestic activities are mainly attributable to the seasonality of gardening. While the rate of those doing heavy housework on at least one day in the week prior to the interview did not substantially differ between the two survey periods (SS: 66.8\%; AW: 69.4\%), there was a remarkable difference in rates of gardening between seasons (SS: 66.3\%; AW: 32.7\%). Unexpectedly, there was no association between season and sporting activities in the getABI cohort. In the literature, there is increasing evidence that physical activity behavior in general is subject to seasonal variations. Twenty-seven out of 37 epidemiological studies reviewed by Tucker and Gilliland [48] revealed an impact of season, and subsequently weather, on physical activity behavior of (older) adults. The highest physical activity levels were registered in the spring and summer months. The study by Sumukadas et al. [49] examined the impact of weather on objectively measured physical activity in functionally impaired elderly on a day-to-day basis. The older persons' physical activity peaked in the summer months, supporting the results of the review. Day length, maximum temperature and sunshine duration were identified as independently associated with daily activity, both at the intra- and interindividual level. Especially for older adults, extreme cold, slippery ground due to precipitation, or early dusk (impaired vision, fear of crime) may constitute barriers to outdoor physical activity in the winter months. Finally, Shephard and Aoyagi [50] pointed out that as physical 
activity fluctuates in the course of the year, so do parameters of physical fitness and health.

\section{Chronic conditions and other physical health-related factors} We hypothesized that specific chronic conditions and other physical health-related factors may have a different impact on sporting and domestic activity level. Analyses revealed that only the need for a walking aid was consistently associated with lower physical activity in both activity categories and sexes. These findings are supported by an Australian study investigating recreational physical activity in 1,500 healthy older women. The proportions of women using a cane were significantly different by activity level, with the highest proportion in the sedentary group $(14.2 \%)$ and the lowest proportion in the high activity group (3.3\%) [51]. Gait unsteadiness due to a loss of lower-body strength and balance, and resulting fear may be an explanation for the decreased activity in older people who depend on a walking aid. Several studies showed that using walking devices is independently associated with being more fearful of falling [52-54]. Fear of falling has in turn been reported as a barrier to physical activity $[26,51,55,56]$. In those with moderate or severe mobility restriction, fear of falling has been even more frequently reported as a barrier to exercise [57]. It has been shown that fear-induced activity reduction [58] or the need for a walking aid [59], and the tendency to adopt a more sedentary lifestyle accelerate functional deconditioning and disability.

The chronic conditions and the remaining physical health-related factors, and their associations with physical activity levels revealed a quite inconsistent picture. Single conditions were found to be associated with one activity category in either women or men, respectively. Only diabetes mellitus was associated with reduced sporting activity in both sexes. Hays et al. [60] studied correlates of overall physical activity in a sample of older diabetics and showed that motivational barriers, i.e. lack of will power, interest and time, were strongly associated with reduced physical activity among these people. It may thus be considered particularly challenging to increase physical activity and especially sporting activity among diabetics.

The cross-sectional design of this study precludes decisions on the direction of associations. However, we speculate that compared to a condition such as hypertension that does not become noticeable during physical activity, the perceptible effects of conditions such as CHF and COPD (e.g. extreme shortness of breath, accelerated fatigue) may cause a reduction in physical activity, like that found for domestic activities in women or sporting activities in men in our study. Additionally, pain may obviously limit the willingness to engage in sporting activities, as was the case for women. A difference in pain intensity as well as disease severity between men and women may explain the inconsistent findings with regard to these health-related conditions and sex. Surprisingly, having osteoporosis increased sporting activity in women. The reasons for this finding are unclear. Further investigations regarding the relevance of health-related factors for engagement in different physical activities are necessary to better understand potential underlying mechanisms of activity restriction based on specific diseases.

\section{Strengths and weaknesses}

The assessment of physical activity in epidemiological research has known limitations [61]. Self-report is subject to bias (recall of activities performed in the past, social desirability bias). However, so far it has been the only way to obtain information on physical activity in different activity domains at low cost and in large populations [62].

Cross-sectional studies have been suggested to be an efficient and empirical means of screening a broad range of potential correlates of physical activity [63]. Associations in fact do not allow causal inferences, but provide a basis for generating hypotheses. The strength of the present study is the inclusion of a broad range of potential, particularly health-related determinants to explore the associations with two categories of activities separately by sex. The omission of measures of perceived health status limits the informative value of our results. We did not consider a broader range of psychological, socio-cultural or environmental variables that have been shown to influence physical activity. This is a limitation of our study.

The response rate of the 7-year follow-up telephone interview was $34.7 \%$. As expected, participants were younger and better educated compared to non-participants. Furthermore, it can be assumed that the willingness and ability to continue to participate in a longitudinal trial after 7 years is higher in healthier persons. Participants who had moved to a nursing home during the follow-up period were no longer able to participate. Therefore, there is most likely a selection towards the fitter patients from baseline to the 7-year follow-up in the getABI cohort. Our results should thus be regarded as relevant for a population of relatively fit seniors who are still able to visit their GP and take part in a telephone interview.

\section{Conclusion}

Despite the above-mentioned limitations, this study delivers reliable and relevant data on the engagement in, and correlates of sporting, and domestic activities of community-dwelling older adults for whom there had been little information at a population level in Germany so far. 


\section{Implications for epidemiological research}

Research on physical activity behavior of older men and women should include the investigation of engagement in diverse physical activities. When merely asking about total physical activity, important information is lost. In our study for instance we might have obtained comparable total physical activity levels for men and women, overlooking women's decreased participation in sporting activities, which has important implications for health promotion practice (see below).

Despite the input of the present study concerning correlates of physical activity, knowledge about the influence of education, living situation, smoking, diverse health-related factors, and season on different categories of physical activity remains inconsistent and unclear. Differentiated epidemiological analyses should attempt to clarify how these and also other factors impact the engagement of older adults in diverse activities such as sports, housework, or gardening, since this could have implications for health promotion practice. When studying the potential impact of physical health-related conditions on physical activity, severity and subjective impairment resulting from each condition should be included. Moreover, the variability of activity prevalence rates in the course of the year has to be considered in the surveillance of physical activity. Finally, a national consensus on a standardized instrument to assess physical activity in older adults is needed to increase comparability of research.

\section{Implications for health promotion practice}

The finding that older men engaged in sporting activities more often while women performed more domestic activities corresponds to conventional role assignment. It has been suggested that domestic activities may compensate for low participation in sporting activity. However, we suppose that performance of heavy housework may not yield the same benefits for health and psychophysical well-being as participation in leisure sporting activities. Health care providers are thus challenged to increase older women's interest of and motivation for sports and exercise, despite a potential lack of experience with practice and higher level of involvement in 'family responsibilities'.

The seasonality of physical activity behavior is of particular relevance for health promotion practice. Health care professionals should sensitize older adults to the seasonal variations in physical activity behavior and the implications for health and functioning. Alternatives to outdoor physical activities should be discussed for the winter months to ideally maintain the physical activity level throughout the year.

Finally, the present study showed that older people who suffer from specific chronic diseases such as CHF and COPD, pain, or impaired mobility probably reduce their sporting or domestic physical activities due to the perceptible impacts of these conditions. They are thus in danger of accelerated functional decline and social withdrawal. Although it may be considered challenging, health care providers should particularly approach older adults with noticeable health and functional impairments in order to motivate them to engage in regular physical activity. These people would greatly profit from individually adapted physical activity programmes in terms of preventing progression of their disease and disability, and preserving their independence and healthrelated quality of life.

\section{Acknowledgements}

From 2001 to 2007, getABI was supported by an unrestricted educational grant from Sanofi-Aventis, Berlin, Germany. Since 2007, the trial has been funded by the German Federal Ministry of Education and Research (01ET0720). The present study was conducted within the PRISCUS research cooperation ("Prerequisites for a new health care model for elderly people with multimorbidity") [64].

\section{Author details}

${ }^{1}$ Department of Sports Medicine and Sports Nutrition, Ruhr-University Bochum, Germany. ${ }^{2}$ Department of Medical Informatics, Biometry and Epidemiology, Ruhr-University Bochum, Germany.

\section{Authors' contributions}

TH and PP obtained the research grant for the project "Physical activity, multimorbidity and polypharmacy in the elderly" within the PRISCUS research cooperation [64] and initiated the specific data collection in the get $\mathrm{ABI}$ cohort. TH coordinated the project. AM and TH conceived the research question and the statistical design of the present study. AM edited the data and performed the statistical analyses. RKM participated in data preparation and double-checked the statistical analyses. AM, TH and UT interpreted the data. AM drafted the manuscript. All authors revised the manuscript critically for important intellectual content. All authors approved the version to be published.

\section{Conflicts of interests}

The authors declare that they have no competing interests.

Received: 22 December 2010 Accepted: 13 July 2011

Published: 13 July 2011

\section{References}

1. Statistisches Bundesamt [Federal Statistical Office], (Ed.): Bevölkerung Deutschlands bis 2060. 12. koordinierte Bevölkerungsvorausberechnung [German population till 2060. 12th coordinated population forecast]. Wiesbaden: Eigenverlag [self-published]; 2009.

2. Blair SN: Physical inactivity: the biggest public health problem of the 21st century. Brit J Sport Med 2009, 43:1-2.

3. Nelson ME, Rejeski WJ, Blair SN, Duncan PW, Judge JO, King AC, Macera CA Castaneda-Sceppa C: Physical activity and public health in older adults: recommendation from the American College of Sports Medicine and the American Heart Association. Circulation 2007, 116:1094-1105.

4. Chodzko-Zajko WJ, Proctor DN, Fiatarone Singh MA, Minson CT, Nigg CR, Salem GJ, Skinner JS: Exercise and physical activity for older adults. Med Sci Sport Exer 2009, 41:1510-1530.

5. Physical Activity Guidelines Advisory Committee, (Ed.): Physical Activity Guidelines Advisory Committee Report 2008. Washington, DC: U.S. Department of Health and Human Services; 2008.

6. U.S. Department of Health and Human Services, (Ed.): 2008 Physical activity guidelines for Americans. Be active, healthy, and happy. 2008 [http://www.health.gov/paguidelines].

7. Rütten A, Abu-Omar K, Lampert T, Ziese T: Heft 26 - Körperliche Aktivität [Issue 26 - Physical activity]. In Gesundheitsberichterstattung des Bundes 
[Federal Health Reporting]. Edited by: Robert Koch-Institut. Berlin: Eigenverlag [self-published]; 2005.

8. Robert Koch-Institut, (Ed.): Beiträge zur Gesundheitsberichterstattung des Bundes - Daten und Fakten: Ergebnisse der Studie "Gesundheit in Deutschland aktuell 2009". [Contributions to Federal Health Reporting Facts and figures: Study results "Health in Germany up-to-date 2009"]. Berlin: Eigenverlag (Vorabdruck) [self-published (preprint)]; 2010.

9. Australian Institute of Health and Welfare, (Ed.): Australia's health 2010. Australia's health series no. 12. Cat. no. AUS 122. Canberra: AlHW; 2010.

10. Craig R, Mindell J, Hirani V, (Eds.): Health Survey for England 2008. Physical activity and fitness. Summary of key findings. The Health and Social Care Information Centre; 2009.

11. Haley C, Andel R: Correlates of Physical Activity Participation in Community-Dwelling Older Adults. J Aging Phys Activ 2010, 18:375-389.

12. Jones DA, Ainsworth BE, Croft JB, Macera CA, Lloyd EE, Yusuf HR: Moderate leisure-time physical activity: who is meeting the public health recommendations? A national cross-sectional study. Arch Fam Med 1998, 7:285-289.

13. Krems C, Lührmann PM, Neuhauser-Berthold M: Physical activity in young and elderly subjects. J Sport Med Phys Fit 2004, 44:71-76.

14. Lawlor DA, Taylor M, Bedford C, Ebrahim S: Is housework good for health? Levels of physical activity and factors associated with activity in elderly women. Results from the British Women's Heart and Health Study. J Epidemiol Commun H 2002, 56:473-478.

15. Ruchlin HS, Lachs MS: Prevalence and correlates of exercise among older adults. J Appl Gerontol 1999, 18:341-357.

16. U.S. Department of Health and Human Services, (Ed.): Physical activity and health: A report of the Surgeon General. Atlanta, GA: Department of Health and Human Services, Centers for Disease Control and Prevention, National Center for Chronic Disease Prevention and Health Promotion; 1996.

17. Ashe MC, Miller WC, Eng JJ, Noreau L: Older Adults, Chronic Disease and Leisure-Time Physical Activity. Gerontology 2008, 55:64-72.

18. Bijnen FCH, Feskens EJM, Caspersen CJ, Giampaoli S, Nissinen AM, Menotti A, Mosterd WL, Kromhout D: Physical activity and cardiovascular risk factors among elderly men in Finland, Italy, and the Netherlands. Am J Epidemiol 1996, 143:553-561.

19. Chad KE, Reeder BA, Harrison EL, Ashworth NL, Sheppard SM, Schultz SL, Bruner BG, Fisher KL, Lawson JA: Profile of physical activity levels in community-dwelling older adults. Med Sci Sport Exer 2005, 37:1774-1784.

20. Walsh JME, Pressman AR, Cauley JA, Browner WS: Predictors of physical activity in community-dwelling elderly white women. $J$ Gen Intern Med 2001, 16:721-727.

21. Yusuf HR, Croft JB, Giles WH, Anda RF, Casper ML, Caspersen CJ, Jones DA Leisure-time physical activity among older adults - United States, 1990. Arch Intern Med 1996, 156:1321-1326.

22. Lührmann PM, Bender R, Edelmann-Schafer B, Neuhauser-Berthold M: Longitudinal changes in energy expenditure in an elderly German population: a 12-year follow-up. Eur J Clin Nutr 2009, 63:986-992.

23. Sallis JF, Cervero RB, Ascher W, Henderson KA, Kraft MK, Kerr J: An ecological approach to creating active living communities. Annu Rev Public Health 2006, 27:297-322.

24. van Stralen MM, De Vries H, Mudde A, Bolman C, Lechner L: Determinants of initiation and maintenance of physical activity among older adults: a literature review. Health Psychology Review 2009, 3:147-207.

25. Cohen-Mansfield J, Marx MS, Guralnik JM: Motivators and barriers to exercise in an older community-dwelling population. J Aging Phys Activ 2003, 11:242-253.

26. Mathews AE, Laditka SB, Laditka JN, Wilcox S, Corwin SJ, Liu R, Friedman DB, Hunter R, Tseng W, Logsdon RG: Older adults' perceived physical activity enablers and barriers: a multicultural perspective. J Aging Phys Activ 2010, 18:119-140.

27. Kaplan MS, Newsom JT, McFarland BH, Lu LN: Demographic and psychosocial correlates of physical activity in late life. Am J Prev Med 2001, 21:306-312.

28. Hinrichs T, Trampisch U, Burghaus I, Endres H, Klaaßen-Mielke R, Moschny A Platen P: Correlates of sport participation among community-dwelling elderly people in Germany: a cross-sectional study. Eur Rev Aging Phys Act 2010, 7:105-115.

29. Leung YW, Ceccato N, Stewart DE, Grace SL: A prospective examination of patterns and correlates of exercise maintenance in coronary artery disease patients. J Behav Med 2007, 30:411-421.
30. Trost SG, Owen N, Bauman AE, Sallis JF, Brown W: Correlates of adults' participation in physical activity: review and update. Med Sci Sport Exer 2002, 34:1996-2001.

31. Becker S, Huy C, Brinkhoff KP, Gomolinsky U, Klein T, Thiel A, ZimmermannStenzel M: "Ein aktives Leben leben" - Sport, Bewegung und Gesundheit im mittleren und höheren Erwachsenenalter - Konzeption, Datenerhebung und erste Ergebnisse eines repräsentativen BasisSurveys für die 50-70-jährige baden-württembergische Wohnbevölkerung ["Living an active life" - Sports, exercise and health in middle-aged and older adults - An empirical database on physical activity, health behavior and lifestyle in the 50- to 70-year-old residential population of Baden-Wuerttemberg]. Gesundheitswesen 2007, 69:401-407.

32. van den Hombergh $C E$, Schouten $E G$, van Staveren WA, van Amelsvoort LG, Kok FJ: Physical activities of noninstitutionalized Dutch elderly and characteristics of inactive elderly. Med Sci Sport Exer 1995, 27:334-339.

33. Zizzi S, Goodrich D, Wu Y, Parker L, Rye S, Pawar V, Mangone C, Tessaro I: Correlates of physical activity in a community sample of older adults in Appalachia. J Aging Phys Activ 2006, 14:423-438.

34. Diehm C, Lange S, Darius H, Pittrow D, von Stritzky B, Tepohl G, Haberl RL, Allenberg JR, Dasch B, Trampisch HJ: Association of low ankle brachial index with high mortality in primary care. Eur Heart J 2006, 27:1743-1749.

35. getABI Study Group: getABI: German epidemiological trial on ankle brachial index for elderly patients in family practice to detect peripheral arterial disease, significant marker for high mortality. VASA-Journal of Vascular Disease 2002, 31:241-248.

36. Arbeitsgruppe Epidemiologische Methoden der Deutschen Arbeitsgemeinschaft Epidemiologie (DAE) [German Working Group Epidemiology]: Leitlinien und Empfehlungen zur Sicherung von guter epidemiologischer Praxis (GEP) - Überarbeitete Fassung nach Evaluation [Guidelines and recommendations for ensuring Good Epidemiological Practice - Revised version after evaluation]. Gesundheitswesen 2005, 67:217-225.

37. Trampisch U, Platen P, Burghaus I, Moschny A, Wilm S, Thiem U, Hinrichs T: Reliabilität des PRISCUS-PAQ. Fragebogen zur Erfassung körperlicher Aktivität von Personen im Alter von 70 Jahren und älter [Reliability of the PRISCUS-PAQ. Questionnaire to assess physical activity of persons at the age of 70 years and older]. Z Gerontol Geriat 2010, 43:399-406.

38. Lamb SE, Jorstad-Stein EC, Hauer K, Becker C: Development of a common outcome data set for fall injury prevention trials: the Prevention of Falls Network Europe consensus. J Am Geriatr Soc 2005, 53:1618-1622.

39. Haskell WL, Lee IM, Pate RR, Powell KE, Blair SN, Franklin BA, Macera CA, Heath GW, Thompson PD, Bauman A: Physical activity and public health: Updated recommendation for adults from the American College of Sports Medicine and the American Heart Association. Med Sci Sport Exer 2007, 39:1423-1434.

40. Centers for Disease Control and Prevention: Prevalence of self-reported physically active adults - United States, 2007. MMWR 2008, 57:1297-1300

41. Sarkin JA, Nichols JF, Sallis JF, Calfas KJ: Self-report measures and scoring protocols affect prevalence estimates of meeting physical activity guidelines. Med Sci Sport Exer 2000, 32:149-156.

42. King AC, Castro C, Wilcox S, Eyler AA, Sallis JF, Brownson RC: Personal and environmental factors associated with physical inactivity among different racial-ethnic groups of US middle-aged and older-aged women. Health Psychol 2000, 19:354-364.

43. Sjogren K, Stjernberg L: A gender perspective on factors that influence outdoor recreational physical activity among the elderly. BMC Geriatr 2010, 10:34

44. Bird S, Kurowski W, Feldman S, Browning C, Lau R, Radermacher H, Thomas S, Sims J: The influence of the built environment and other factors on the physical activity of older women from different ethnic communities. J Women Aging 2009, 21:33-47.

45. Bundesministerium für Familien, Senioren, Frauen und Jugend (BMFSFJ) [Federal Ministry for Families, Seniors, Women and Youth], (Ed.): Frauen in Deutschland [Women in Germany]. Berlin; 2004.

46. Tesch-Römer C, Wurm S: Gesundheit im Alter bedingt durch Schicksal, Schichtzugehörigkeit und Verhalten? Gesundheitsrelevante Lebenslagen und Lebensstile [Health in old age due to fate, social class and behaviour? Health-relevant circumstances and lifestyles]. In Gesundheit und Krankheit im Alter - Beiträge zur Gesundheitsberichterstattung des Bundes [Health and morbidity in old age - Contributions to Federal Health Reporting]. 
Edited by: Statistisches Bundesamt Deutsches Zentrum für Altersfragen, Robert Koch-Institut. Berlin: Eigenverlag [self-published]; 2009:.

47. Baumgartner B, Halder L, Kolip P, (Eds.): Qualitative Interviewstudie mit 50bis 65-jährigen, alleinlebenden Bremerinnen und Bremern sowie Bremer Experten zum dem Thema: Wohnen im Alter in Bremen. Endbericht [Qualitative interview survey in solitarily living 50-to-65-year-old men and women from Bremen, and in experts with regard to habitation in old age in Bremen. Final report]. Institut für Public Health und Pflegeforschung, Universität Bremen [Institute for Public Health and Research in Nursing, University of Bremen]; 2009.

48. Tucker P, Gilliland J: The effect of season and weather on physical activity: a systematic review. Public Health 2007, 121:909-922.

49. Sumukadas D, Witham M, Struthers A, McMurdo M: Day length and weather conditions profoundly affect physical activity levels in older functionally impaired people. J Epidemiol Community Health 2009, 63:305-309.

50. Shephard RJ, Aoyagi Y: Seasonal variations in physical activity and implications for human health. Eur J Appl Physiol 2009, 107:251-271.

51. Bruce DG, Devine A, Prince RL: Recreational physical activity levels in healthy older women: The importance of fear of falling. J Am Geriatr Soc 2002, 50:84-89.

52. Howland J, Peterson EW, Levin WC, Fried L, Pordon D, Bak S: Fear of falling among the community-dwelling elderly. J Aging Health 1993, 5:229-243.

53. Kressig RW, Wolf SL, Sattin RW, O'Grady M, Greenspan A, Curns A, Kutner M: Associations of demographic, functional, and behavioral characteristics with activity-related fear of falling among older adults transitioning to frailty. J Am Geriatr Soc 2001, 49:1456-1462.

54. Lachman ME, Howland J, Tennstedt S, Jette A, Assmann S, Peterson EW: Fear of falling and activity restriction: the survey of activities and fear of falling in the elderly (SAFE). J Gerontol B Psychol Sci Soc Sci 1998, 53 : P43-50.

55. Lees FD, Clark PG, Nigg CR, Newman P: Barriers to exercise behavior among older adults: A focus-group study. J Aging Phys Activ 2005, 13:23-33.

56. Wilcox S: Physical activity in older women of color. Top Geriatr Rehabil 2002, 18:21-33.

57. Rasinaho M, Hirvensalo M, Leinonen R, Lintunen T, Rantanen T: Motives for and barriers to physical activity among older adults with mobility limitations. J Aging Phys Act 2007, 15:90-102.

58. Deshpande N, Metter EJ, Lauretani F, Bandinelli S, Guralnik J, Ferrucci L: Activity restriction induced by fear of falling and objective and subjective measures of physical function: a prospective cohort study. $J$ Am Geriatr Soc 2008, 56:615-620.

59. Mahoney JE, Sager MA, Jalaluddin M: Use of an ambulation assistive device predicts functional decline associated with hospitalization. $J$ Gerontol a-Biol 1999, 54:M83-M88.

60. Hays LM, Clark DO: Correlates of physical activity in a sample of older adults with type 2 diabetes. Diab Care 1999, 22:706-712.

61. Jorgensen $T$, Andersen LB, Froberg K, Maeder U, Von Huth Smith L, Aadahl M: Position statement: Testing physical condition in a population - how good are the methods? European Journal of Sports Science 2009, 9:257-267.

62. Lamonte MJ, Ainsworth BE: Quantifying energy expenditure and physical activity in the context of dose response. Med Sci Sport Exer 2001, 33 S370-S378

63. Bauman AE, Sallis JF, Dzewaltowski DA, Owen N: Toward a better understanding of the influences on physical activity - The role of determinants, correlates, causal variables, mediators, moderators, and confounders. Am J Prev Med 2002, 23:5-14.

64. Thiem U, Theile G, Junius-Walker U, Holt S, Thurmann P, Hinrichs T, Platen $\mathrm{P}$, Diederichs $\mathrm{C}$, Berger $\mathrm{K}$, Hodek JM, et al: Prerequisites for a new health care model for elderly people with multimorbidity: The PRISCUS research consortium. Z Gerontol Geriat 2010, 44:115-120.

\section{Pre-publication history}

The pre-publication history for this paper can be accessed here: http://www.biomedcentral.com/1471-2458/11/559/prepub

\section{doi:10.1186/1471-2458-11-559}

Cite this article as: Moschny et al:: Physical activity patterns in older men and women in Germany: a cross-sectional study. BMC Public Health 2011 11:559.

\section{Submit your next manuscript to BioMed Central and take full advantage of:}

- Convenient online submission

- Thorough peer review

- No space constraints or color figure charges

- Immediate publication on acceptance

- Inclusion in PubMed, CAS, Scopus and Google Scholar

- Research which is freely available for redistribution

Submit your manuscript at www.biomedcentral.com/submit
Biomed Central 